\title{
Le songe éternel
}

\author{
Daniel José Villalta Brenes
}

$\mathbf{J}$ e la tenais entre mes sanglantes mains, comme s'il s'agissait d'un morceau de viande. Je ne savais quoi faire. Cette femme, celle que j'avais promis de la protéger et de l'aimer, je pouvais sentir sa vie s'écouler au long de mes doigts. " Je ne suis pas un criminel ", je me disais plusieurs fois. Je sentais comment mon sang se gelait. Le battement de mon cour perforait mes tympans, et je ne voyais que du rouge partout. " Mais, je me demandais pendant que les sirènes de la police s'approchaient, comment étais-je arrivé jusqu'ici ?"

Elle suivait le même cours d'Histoire de l'art que moi. Le premier jour de classe, le professeur nous avait dit de nous mettre à deux pour commencer un travail de recherche. À ce moment-là, je ne connaissais personne, donc j'ai demandé à la camarade quiétait devant moi si elle s'était déjà mise avec quelqu'un. Je n'avais pas vu son visage, et lorsqu'elle tournait sa tête, je l'ai découverte, d'une beauté inimaginable pour moi.

Oui, je me suis gelé tout de suite. Le temps s'est arrêté pour une heure ou pour une année, je ne sais plus la différence. Je voyais ses rouges et pulpeuses lèvres bouger, mais je n'entendais rien. Ses grands yeux dorés m'ont lancé vers une transe qui me semblait difficile à comprendre. Ses cheveux raides et cuivrés reposaient sur ses délicates épaules et bougeaient si élégamment qu'elle n'aurait pas pu échapper au regard des autres. Ses cils, fins et longs, couvraient de temps en temps la lumière éclatante que projetaient ses pupilles. Juste au-dessous de ses yeux, quelques taches de rousseur dansaient dans ses roses joues. Du coup, elle m'avait ensorcelé.

Soudain, je suis revenu au monde réel. Elle ne cessait point de me demander mon prénom. "Xavier ", j’ai finalement dit. Elle s'appelait Martine, et sa famille vivait près de la mienne à Twickenham. Elle parlait trop vite, mais avec une légèreté naturelle que je trouvais fascinante. J'étais complètement submergé dans sa façon d'être. Je la regardais comme un enfant regarde un magicien. Il y a eu un attrait réciproque dès ce jour-là.

Je commençais à bien la connaître. Elle n'aimait pas le chocolat mais adorait les desserts. Elle haïssait la consommation excessive de n'importe quoi, mais elle aimait chiner et acheter toute sorte de robes, chemises, pantalons, jupes, chaussures, écharpes, boucles, colliers, lunettes, sandales, bottes... La lecture par plaisir l'effarouchait, mais 
elle pouvait sans aucun souci se mettre à lire la théorie de son cursus pendant plusieurs heures. Elle aimait la nature mais détestait les cactus car ils étaient " trop verts ». Enfin, elle a dû s'appeler "Contradiction " puisque dans sa vie, il n'y avait que cela.

J'ai découvert tout cela pendant le temps que l'on travaillait ensemble pour la recherche. Nous avons éprouvé une chimie incroyable, c'était quelque chose que je n'avais jamais vécu. Après avoir réussi le cours, nous sommes restés en contact. Je l'invitais à dîner de fois en fois, et on se voyait presque tous les jours. J'ai appris à cuisiner surtout grâce à ce qu'elle aimait collectionner des recettes (et, pourtant, elle détestait cuisiner).

C'était la dernière année de notre cursus, et je commençais à travailler dans une maison d'édition et elle dans une bibliothèque. Cependant, on se voyait encore beaucoup. Donc, j'ai décidé de lui poser la question que je craignais... Elle m'a répondu : "Oui. »

Je m'éclatais. Je n'avais jamais été quelqu'un de sociable, sinon plutôt timide. Je ne pouvais pas le croire. Les relations que j'avais eues avaient été difficiles puisque j'étais trop dominant. Ce n'est pas de ma faute... Je voulais seulement sentir que quelque chose m’appartenait vraiment. Malgré ces expériences, j'étais résolu que cette fois-ci ce serait différent.

Depuis sept mois merveilleux, nous avons commencé à vivre ensemble. J'étais sûr qu'elle était pour moi. Martine n'était pas complètement sûre de mon compromis puisqu'elle ne croyait pas que j'en étais vraiment amoureux.

- Ma chère, je lui ai dit, je suis à toi. Il n'y a personne aussi belle, aussi géniale et aussi extraordinaire que toi.
Je ne peux pas vivre sans tes bêtises ou sans ton sourire. Ces derniers mois ont été un rêve pour moi, et je ne veux pas me réveiller. Tu sais? Je ne suis rien sans toi. Crois-moi, tu es ma vie.

- Regarde, Xavier - elle m'a répondu presque en pleurant - je te crois. Je t'offre tout ce que je suis. Mes rêves, mes peurs, ma vie toute je veux la partager avec toi.

Nous nous sommes embrassés comme jamais et je me croyais, l'homme le plus heureux du monde. Je ne savais pas que dès ce moment-là nos vies tourneraient vers un abîme incontournable.

Les premières semaines ensemble ont été excellentes. C'était la stabilité que je cherchais depuis toujours. Je voyais Martine heureuse, active et souriante tout le temps. J'étais vraiment au ciel, je vous jure. Je la regardais et je pouvais me voir... Cependant, après deux mois, elle avait changé son humeur de pied en cap. Elle ne me parlait qu'avec des monosyllabes, elle semblait distante et froide, et elle sortait de chez nous sans rien dire.

J'étais préoccupé. L'image d'elle avec un autre homme hantait mes pensées. Néanmoins, je ne lui ai rien demandé car je ne voulais pas l'ennuyer. Elle ne s'est pas arrêtée pour me parler ni pour m'embrasser. Je devenais de plus en plus anxieux, mais je demeurais en silence. Chaque jour qui se passait, plus je m'inquiétais. Elle venait, elle s'en allait... Je la voyais par la fenêtre, et de différentes voitures arrivaient l'emmener quelque part et la ramener chez nous. Je ne mangeais pas, et j'avais peur. J'avais une peur qui montait plus fort chaque minute, chaque seconde... Une peur que je ressentais dans ma peau. Cette peur 
montait tellement vite que, d'un jour à l'autre, elle s'est transformée en colère. Je détestais passionnément Martine. Je suis passé de l'aimer à ne pas vouloir la regarder au cours d'une semaine.

Vendredi est arrivé, et elle finalement m'a dit quelque chose. "Je t'aime, Xavier. ", c'étaient ses mots exacts. Qu'est-ce qu'elle voulait me dire avec ces paroles ? Est-elle devenue folle ? Suis-je devenu fou ? Deviendra-t-elle celle que je connaissais?

Tandis que je me posais ces questions, là elle est partie. Je me suis senti désorienté tout de suite. La rage hissait dans moi, et ma tête s'alourdissait. Son image dans ma mémoire commençait à changer. Ses cheveux cuivrés se déformaient et tombaient un à un par terre. Ses yeux, une fois éclatants, s'assombrissaient peu à peu jusqu'au point de n'être que deux grands et profonds puits noirs. Sa délicate silhouette s'est altérée de façon qu'elle ne me semblait plus humaine. Elle s'est métamorphosée. À ce moment-là, à mes yeux elle était un monstre.

Elle est revenue lundi soir. Je n'ai pas perdu une minute. Je me suis lancé aveuglement contre elle au moment où elle est entrée chez nous. Je ne vous choquerez pas avec trop de détails car la scène était affreuse. Les cris, les dents, le sang mêlé avec la sueur, les coups de poings... Le silence. Je la regardais, et je me suis mis à pleurer. Je me suis rendu compte de ce que je venais de faire. "Je ne suis pas un criminel ", me disais-je plusieurs fois. Je sentais comment mon sang se gelait. Le battement de mon cœur perforait mes tympans, et je ne voyais que du rouge partout. "Mais, je me demandais pendant que les sirènes de la police s'approchaient, comment étais-je arrivé jusqu'ici ?»

Je me suis réveillé.

Le professeur a recommencé la classe, donc elle s'est retournée. J'étais encore gelé, cette fois-ci à cause de ce que j'avais vu. "Qu'est-ce que c'était cela ? " Je ne pouvais penser qu'à cela. Mon Dieu, quelle folie ! Tout n'était que de mon imagination. Je pouvais respirer tranquillement, et je souriais. Le professeur avait déjà choisi les couples pour l'infâme travail de recherche et il lisait la liste. "Xavier et Martine ", a-t-il dit.

Martine s'est tournée et m'a lancé un regard étrange, mais je savais ce qu'elle allait me demander:

- Alors, vous êtes Xavier, n'est-ce
pas ?
- Vous avez raison.
- Vous me semblez familier...

Est-ce nous nous connaissons?

- Par cœur, Martine. Par cœur. 
